\title{
PRIMEIRO RELATO DE Aceria litchii (KEIFER) (PROSTIGMATA: ERIOPHYIDAE) EM PLANTAS DE LICHIA NO BRASIL
}

\author{
ADALTON RAGA ${ }^{2}$, JEFERSON LUIZ DE CARVALHO MINEIRO ${ }^{3}$, MÁRIO EIDI SATO $^{4}$, \\ GILBERTO JOSÉ DE MORAES ${ }^{5}$, CARLOS HOLGER WENZEL FLECHTMANN ${ }^{6}$
}

RESUMO - O ácaro-da-erinose-da-lichia, Aceria litchii (Keifer), é relatado pela primeira vez no Brasil, na região central do Estado de São Paulo, causando dano severo a folhas e frutos jovens. Esta espécie era citada como praga quarentenária A1 para o Brasil.

Termos para indexação: Litchi chinensis, praga quarentenária, ácaro-da-erinose-da-lichia

\section{FIRST REPORT OF Aceria litchii (KEIFER) (PROSTIGMATA: ERIOPHYIDAE) ON LITCHI TREES IN BRAZIL}

\begin{abstract}
The litchi erinose mite, Aceria litchii, is reported for the first time in Brazil in the central region of the State of São Paulo, causing severe damage to newly developed leaves and fruits. This species was listed as an A1 quarantine pest in Brazil.
\end{abstract}

Index terms: Litchi chinensis, quarantine pest, litchi erinose mite.

A lichieira, Litchi chinensis Sonn. (Sapindaceae), é oriunda da China meridional, onde é cultivada há 40 séculos, sendo hoje extensivamente cultivada no sudoeste asiático (GOMES, 1975; MARTINS et al., 2001). A cultura da lichia vem despertando crescente interesse no Brasil, devido ao aumento da demanda no mercado varejista e ao valor no mercado internacional. Até o início deste século, a lichieira era cultivada em cerca de 350 ha no Estado de São Paulo (MARTINS et al., 2001).

Aceria litchii (Keifer) (Eriophyidae), conhecido como ácaro-da-erinose-da-lichia, é uma das principais pragas da cultura de lichia na Austrália, China, Havaí, Índia, Pasquistão e Taiwan (JEPPSON et al., 1975; SABELIS; BRUIN, 1996; WAITE; HWANG, 2002; HUANG, 2008). Este ácaro infesta brotações, provocando deformações nas folhas e erinose na página inferior (JEPPSON et al., 1975), além de inflorescências e frutos (MARTINS et al., 2001), provocando perda na produção (ALAM; WADUD, 1963). Waite e Hwang (2002) afirmam que A. litchii pode transmitir uma alga, indutora da erinose, com a qual estabelece uma relação simbiótica. Segundo Alam e Wadud (1963), os estômatos da planta ficam bloqueados pela erinose, prejudicando o processo de fotossíntese, além de provocar queda de folhas e frutos.

As fêmeas de $A$. litchii ovipositam na superfície inferior da folhas, no interior do eríneo, provocado por sua alimentação. Os ovos medem 0,032 mm de diâmetro, têm formato esférico, são colocados isoladamente e são translúcido. Cerca de 13 dias após a oviposição, emergem os adultos, medindo cerca de $0,13 \mathrm{~mm}$ de comprimento. No Paquistão, vivem cerca de oito meses na forma ativa e quatro meses em condições de dormência (ALAM; WADUD, 1963). O ácaro-da-erinose também infesta plantas de Dimocarpus longan (HUANG, 2008), também uma Sapindaceae.

De acordo com Waite (1999), além da disseminação espontânea, espécimes de $A$. litchii ficam aderidos ao corpo das abelhas, quando estas visitam as inflorescências, sendo esses ácaros transportados e disseminados para outras plantas do mesmo pomar.

No Brasil, A. litchii foi listada em 2007, como praga quarentenária $\mathrm{A} 1$, de acordo com a Instrução Normativa 52 do Ministério da Agricultura,

\footnotetext{
(Trabalho 082-09). Recebido em: 07-04-2009. Aceito para publicaçaõ em: 25-09-2009.

${ }^{2} \mathrm{Eng}^{\mathrm{o}} \mathrm{Agr}^{\mathrm{o}}$, Pesquisador Científico, Doutor, Instituto Biológico, Pesquisador do CNPq, Campinas, SP, adalton@biologico.sp.gov.br ${ }^{3}$ Biólogo, Doutor, Instituto Biológico, Campinas, SP, jmineiro@biologico.sp.gov.br

${ }^{4} \mathrm{Eng}^{\mathrm{o}} \mathrm{Agr}^{\mathrm{0}}$, Pesquisador Científico, Doutor, Instituto Biológico, Pesquisador do CNPq, Campinas, SP, mesato@biologico.sp.gov.br ${ }^{5} \mathrm{Eng}^{\mathrm{O}} \mathrm{Agr}^{\mathrm{o}}$, Professor Associado, Universidade de São Paulo, ESALQ, Pesquisador do CNPq, Piracicaba - SP, gjmoraes@esalq.usp.br ${ }^{6} \mathrm{Eng}^{\circ} \mathrm{Agr}^{\circ}$, Professor Aposentado, Universidade de São Paulo, ESALQ, Pesquisador do CNPq, Piracicaba - SP, chwflech@esalq.usp.br
} 
Pecuária e Abastecimento (BRASIL, 2007). Em um levantamento de ácaros em plantas de lichia, realizado em anos anteriores no Estado de São Paulo, não foi constatada a presença do ácaro-daerinose (MINEIRO; RAGA, 2003). Nos meses de julho e agosto de 2007, foram observados sintomas severos do ataque de $A$. litchii em plantas de lichia nos municípios paulistas de Tambaú e Casa Branca, contudo não foi capturado nenhum ácaro dessa espécie. Em fevereiro de 2009, sintomas severos provocados pelo ácaro-da-erinose foram observados pelos autores em pomar de lichia, no município de Mogi-Guaçu (SP), sem a obtenção de o ácaro nas amostras coletadas. Em abril de 2008, no município de Limeira, em pomar comercial da variedade Bengal, com 13 anos de idade, foi detectada a presença de A. litchii em folhas, cujos sintomas de erinose

\section{REFERÊNCIAS}

ALAM, M.Z.; WADUD, M.A. On the biology of litchi mite, Aceria litchi Keifer (Eriophyidae, Acarina) in East Pakistan. Pakistan Journal of Science, Lahore, v. 15, p. 232-240, 1963.

BRASIL. Ministério da Agricultura, Pecuária e Abastecimento. Instrução Normativa 52. Dez 2007. Disponível em: <www.extranet.agricultura.gov.br/ sislegis-consulta/18316. Acesso em: 6 mar. 2008

GOMES, P. Fruticultura brasileira. 2. ed. São Paulo: Nobel, 1975. 446 p.

HUANG, K. Aceria (Acarina: Eriophyoidea) in Taiwan: five new species and plant abnormalities caused by sixteen species. Zootaxa, New Zealand, v. 1829, p. 1-30, 2008.

JEPPSON, L.R.; KEIFER, H.H.; BAKER, E.W. Mites injurious to economic plants. Berkeley: Univ. California, 1975. 641p.

MARTINS, A.B.G.; BASTOS, D.C.; SCALLOPI JÚNIOR, E.J. Lichieira (Litchi chinensis Sonn). Jaboticabal: Sociedade Brasileira de Fruticultura, 2001. 48p. foram inicialmente observados pelo proprietário em janeiro do mesmo ano. Nessa ocasião, as 3.000 plantas do referido pomar apresentavam folhas novas e desenvolvidas com algum grau de sintoma de $A$. litchii, sendo parte das plantas com nível severo de ataque. Trata-se do primeiro registro de $A$. litchii $\mathrm{em}$ lichieiras no Brasil.

Tendo em vista que o controle de E. litchii exige medidas de alto custo financeiro, como poda das plantas e pulverização de acaricidas, é necessária uma rigorosa vistoria de mudas em viveiros, para evitar a disseminação da praga para novas áreas de produção. Tais medidas de controle e prevenção da disseminação do ácaro-da-erinose são fundamentais para evitar a dispersão e o estabelecimento da praga, visto que, segundo Waite (1999), todas as cultivares de lichia são suscetíveis ao ácaro-da-erinose na Austrália.

MINEIRO, J.L.C.; RAGA, A. Ocorrência de ácaros (Arachnida: Acari) em plantas de lichia (Litchi chinensis Sonn.) (Sapindaceae) no Estado de São Paulo. In: REUNIÃO ANUAL DO INSTITUTO BIOLÓGICO, 16., 2003 Anais...São Paulo: Instituto Biológico, 2003. p. 1-4. CD-ROM.

SABELIS, M.W.; BRUIN, J. Evolutionary ecology: life history patterns, food plant choice and dispersal. In: LINDQUIST, E.E.; SABELIS, M.W.; BRUIN, J. (Eds.). World crop pests: Eriophyoid mites, their biology, natural enemies and control. Amsterdam: Elsevier, 1996. v.6, p. 329-365.

WAITE, G.K. New evidence further incriminates honey-bees as vectors of lychee erinose mite Aceria litchi (Acari: Eryophyidae). Experimental and Applied Acarology, London, n.23, p. 145-147, 1999.

WAITE, G.K.; HWANG, J.S. Pests of litchi and longan. In: PEÑA, J.E.; SHARP, J.L.; WYSOKI, M. (Eds.). Tropical fruit pests and Pollinators: biology economic importance, natural enemies and control. Wallingford: CABI, 2002. p. 331-359. 